\title{
INTELLIGENT TECHNOLOGY FOR ESTIMATING OF URBAN ENVIRONMENT QUALITY
}

\author{
Igor PATRAKEYEV ${ }^{1}$ D, Victor ZIBOROVI ${ }^{1}$, Oleksii MIKHNO ${ }^{2}$
}

DOI: $10.21163 / G T \_2020.152 .15$

\begin{abstract}
:
During transiting to the post-industrial era the role of cities and urban environment functions are transformed. A new type of economic system imposes new requirements to the urban environment as a space for the population life and doing business. Today, on the basis of the concept of sustainable development, a general scientific paradigm of cognition is being formed as a result of the synthesis of sciences about nature, society and man. There are many approaches to the concept of sustainable development. The most modern concept, according to the authors of the article, understands of sustainable development, which is based on laws of the conservation of energy or power, as a general law of Nature. The article proposes a comprehensive approach based on the integration of the capabilities of modern GIS and intelligent technologies for estimating the potential, real and missed opportunities of the urban environment in the context of using incomplete and fuzzy information. The application of the proposed approach to estimating the sustainable development of the urban environment on the example of Ukrainian cities is shown.
\end{abstract}

Key-words: spatial database, knowledge base, fuzzy information, indicator of sustainable development, urban environment.

\section{INTRODUCTION}

In the last decade, the problem of using intelligent technologies in the study of sustainable urban development has acquired particular importance. This is due to the strengthening of the role of information and communication channels in the world in general and with the actualization of the introduction of information technology in the legal field of state and municipal management. At one time, Aristotle argued that human society governance is a major component of the development process.

The transition to a new paradigm of sustainable development is discussed at international conferences under the auspices of the United Nations since 1999 (Bolshakov \& Kuznetsov, 2010). This paradigm provides for a constant increase in free energy. In modern models of sustainable development the capacity is used as a measure of development of the system (Bolshakov \& Ryabkova, 2009; Hasanova et al., 2019; Patrakeyev et al., 2017).

There are three groups of system capabilities with a measure of power (Bolshakov, 2007; Newman, 2004). The first group is a potential. It is determined by the measure of full input power to the system. The second group is a real possibility. It is defined as the useful (active) power output of the system. The third group is a lost opportunity. It is determined by the amount of power, which losses on the system output.

It should be noted that to ensure decision-making on sustainable development management, it is necessary to estimate the potential, real and missed opportunities of the urban environment. This estimation is based on the receipt and processing of non-numeric, inaccurate and incomplete information (Shtovba et al, 2016). Non-numeric, inaccurate and incomplete information on the condition of such complex system as the urban environment is used to obtain an integrated estimation

\footnotetext{
${ }^{1}$ Kyiv National University of Construction and Architecture, Faculty of Geoinformation systems and territory management technologies,03037, Kyiv,Ukraine,ipatr@ukr.net; ziborov@ukr.net

${ }^{2}$ Taras Shevchenko National University of Kyiv, Faculty of Geography, 03127, Kyiv, Ukraine, almikhno@ukr.net
} 
of sustainable development based on the estimation of potential, actual and lost opportunities of the urban environment.

The aim of the article is to develop the intelligent technology for making decisions on managing the sustainable urban development based on potential, real and lost opportunities of the urban environment. Using the proposed intellectual technology, an integral estimation of the sustainable development of the urban environment and its individual subsystems, is obtained on Ukrainian cities Odessa and Kryvyi Rih. A comparison of the integrated estimations of sustainable development with the level of sustainable development of European cities is made (Sustainable Urban Metabolism for Europe, 2009).

\section{CONCEPT OF SUSTAINABLE DEVELOPMENT OF URBAN ENVIRONMENT}

Modern science of sustainable development is based on the fundamental laws of the real world. Modern research on sustainable development states that the laws of power conservation are the foundation of the science of sustainable development. A system is open if and only if it exchanges energy flows with the environment. A fundamental feature of open systems is the fact that the total flow $\mathrm{N}$ at the entrance to the system is equal to the sum of the active $\mathrm{P}$ and passive $\mathrm{L}$ (or loss) flows at the exit from the system (Bettencour et al., 2007; Bolshakov \& Ryabkova, 2009; Yanitsky, 2013):

$$
N=P+L=\text { const, }
$$

From the expression (1) it follows that the loss power (L) is under control of the total $(\mathrm{N})$ and useful (P) powers. A decrease in loss power (L) can be achieved (assuming constant full power) only by increasing the net $(\mathrm{P})$ power (productivity), which, in turn, depends on increasing the efficiency of using a full $(\mathrm{N})$ power. That is connected with using modern innovative technologies, improving the quality of production, using renewable energy sources, optimizing the rotation of household and industrial waste, improving the safety of the population, increasing mobility population by improving public transport and more (Kennedy et al., 2015).

We define a set of subsystems of the urban environment that are most important to ensure the concept of sustainable development. Such subsystems may be (Acebillo, 2013; Giordano et al., 2014; Paola et al, 2016):

- transport subsystem, which provides the mobility of population;

- subsystem of city economy, which characterizes conditions of population comfortable life;

- socio-economic subsystem, that provides a healthy standard of living for the population.

The interaction scheme of considered subsystems of urban environment in accordance with expression (1) is shown in Fig.1. Supporting the life of urban environment is the circulation of substances. This energy is necessary for the vital activity of living organisms, as well as for the production of materials, substances, products, resources and services.

Each subsystem receives a certain amount of different types of energy, matter and information $\mathrm{N}(\mathrm{t})$. In this case, the subsystem produces two types of products. One type is negative production, it is determined by the loss stream $\mathrm{L}(\mathrm{t})$. The second type of product is used by each subsystem to ensure its own life, this is a flow of useful work $\mathrm{P}(\mathrm{t})$.

The information model of the interaction of city economy subsystem of the urban environment with the environment is shown in Fig.2 (Acebillo, 2013). Indicators of the total flows of matter, energy, information, as well as indicators of the flow of losses and indicators of the negentropic flow of the subsystem of urban economy have a heterogeneous and multi-scale character.

For example, the real opportunity of the subsystem of urban economy is determined by such indicators of flows of matter, energy and information: the population density with dimensionality in person/ha; building density with dimensionality $\mathrm{m}^{2} / \mathrm{ha}$; building density coefficient with dimensionality $\mathrm{m}^{2} / \mathrm{ha}$; annual energy consumption for heating residential buildings with dimensionality MWh/year; annual water supply in residential buildings with dimensionality 1/person; total electricity consumption in residential buildings with dimensionality $\mathrm{kWh} / \mathrm{year}$. 


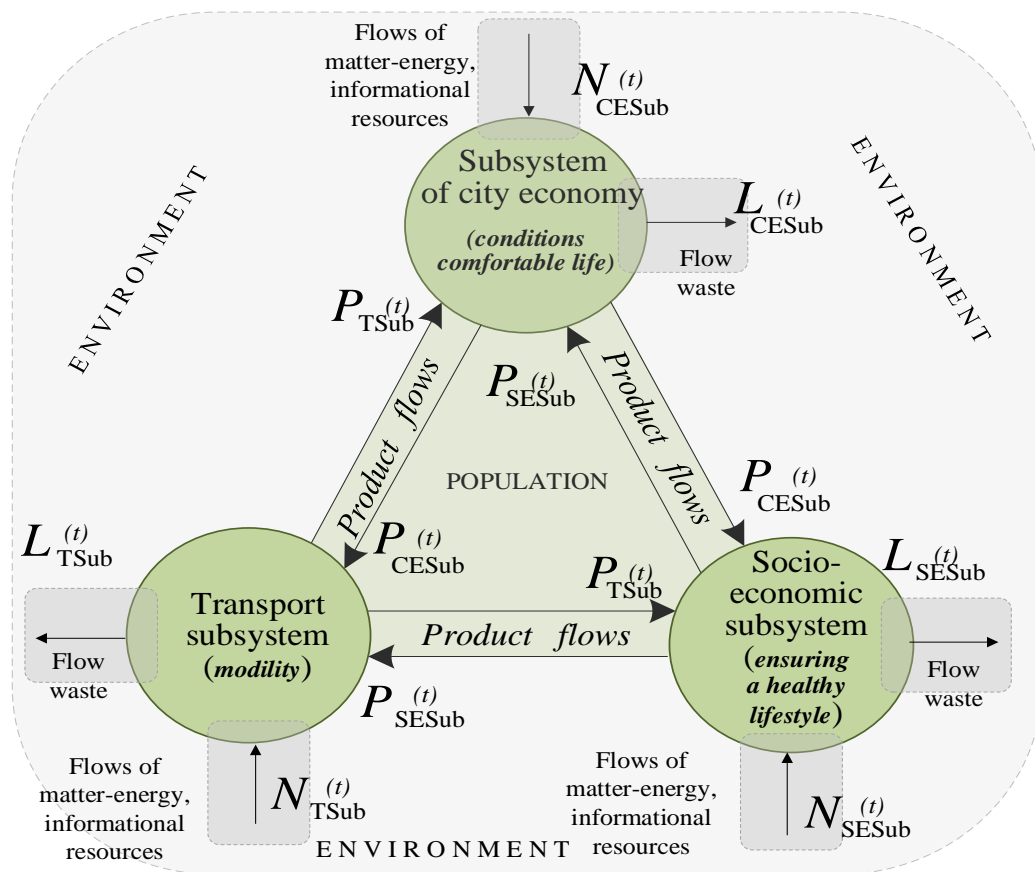

Fig. 1. Scheme of exchange of material resources, information and energy between the environment and subsystems of urban environment.

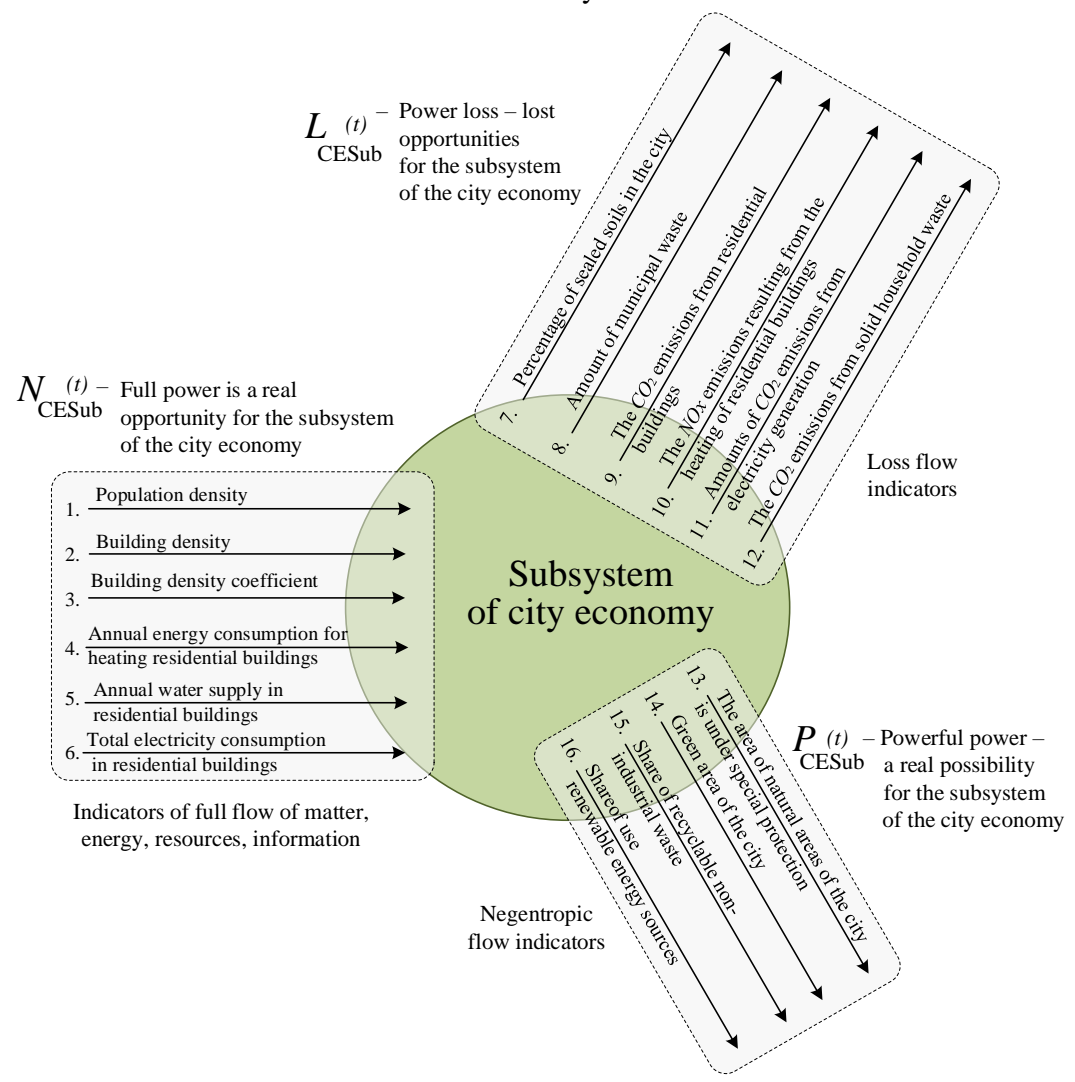

Fig. 2. Information model of the interaction of subsystem of city economy with the environment. 
Thus, we have measured flows of different nature. Table 1 shows an example of indicators of material and energy flows of urban environment for subsystem of city economy, which includes 16 indicators (see Fig. 2).

Table 1.

Example of indicators of material and energy flows of urban environment

(city economy subsystem)

\begin{tabular}{|c|c|c|c|c|c|c|}
\hline \multicolumn{2}{|r|}{ Indicators of material and energy flows } & Designation & $N(t)$ & $P(t)$ & $L(t)$ & Units of measurement \\
\hline 1. & Population density & $I_{1}$ & ? & & & inhabit. /ha \\
\hline 2. & Building density & $I_{2}$ & $\bullet$ & & & $m^{2} / h a$ \\
\hline 3. & Building density coefficient & $I_{3}$ & 0 & & & $m^{2} / h a$ \\
\hline \multicolumn{2}{|r|}{.... } & \multicolumn{3}{|l|}{.... } & \multicolumn{2}{|r|}{.... } \\
\hline 8. & Amount of household waste & $I_{8}$ & & & - & kg/inhabit. \\
\hline \multicolumn{2}{|r|}{.... } & \multicolumn{3}{|l|}{.... } & \multicolumn{2}{|r|}{$\ldots . .}$. \\
\hline 11. & $\begin{array}{l}\text { Amounts of } \mathrm{CO}_{2} \text { emission from } \\
\text { electricity generation }\end{array}$ & $I_{11}$ & & & 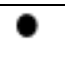 & $\mathrm{kg} /\left(\mathrm{m}^{2} \cdot\right.$ year $)$ \\
\hline \multicolumn{2}{|r|}{$\ldots}$. & \multicolumn{3}{|l|}{.... } & \multicolumn{2}{|r|}{.... } \\
\hline 16. & $\begin{array}{l}\text { Share of using renewable energy } \\
\text { sources }\end{array}$ & $I_{16}$ & & 0 & & $\%$ \\
\hline
\end{tabular}

Depending on types of spatial objects to which they are applied, indicators of material and energy flows can be generalized (have a single value) or distributed (over the territory or along the length of linear object). Distributed over the territory indicator $\mathrm{I}_{2}$ - building density as a GRID-surface for cities Krivyi Rih, Odessa, Lugano and Barcelona are presented in Fig. 3 as an example.

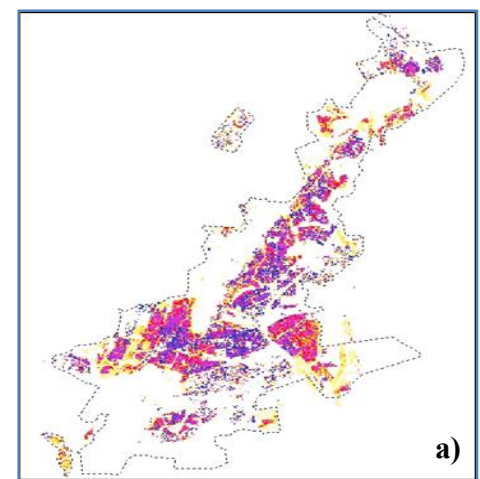

0

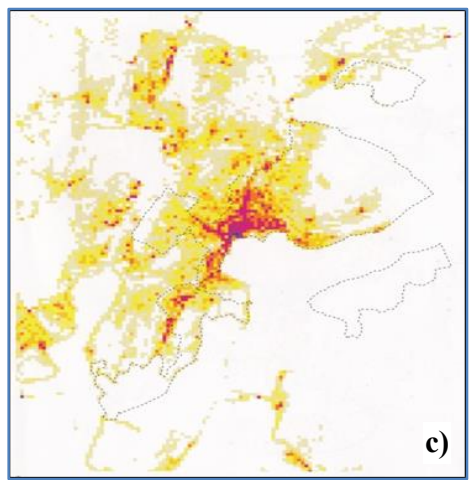

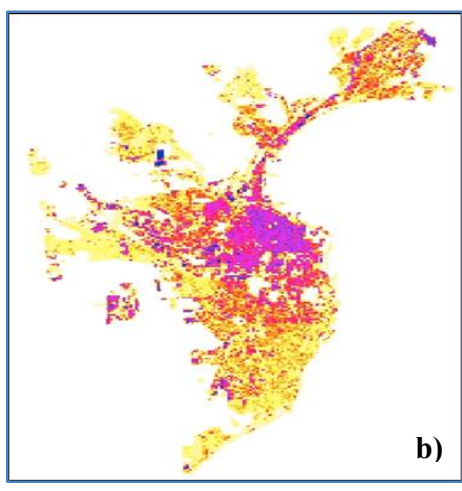

$100 \%$

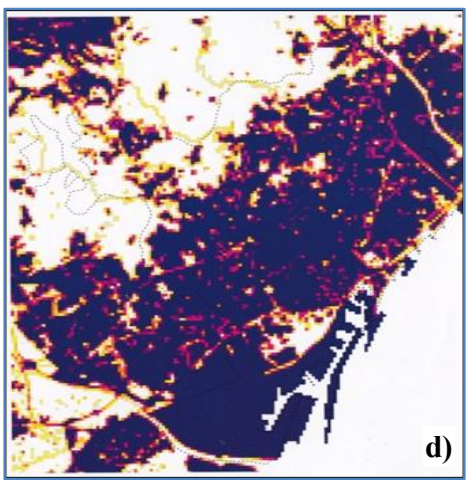

Fig. 3. Examples of indicator $I_{2}$ for cities (a) Krivyi Rih, (b) Odessa, (c) Lugano and (d) Barcelona. 


\section{INTELLIGENT TECHNOLOGY FOR ESTIMATING OF SUSTAINABLE DEVELOPMENT OF URBAN ENVIRONMENT}

The proposed intelligent technology for estimating the sustainable development of urban environment based on an indicator of metabolic efficiency is shown in Fig.4 (Mikhno \& Patrakeyev, 2018; Patrakeyev \& Ziborov, 2019). The technology consists of four main steps.

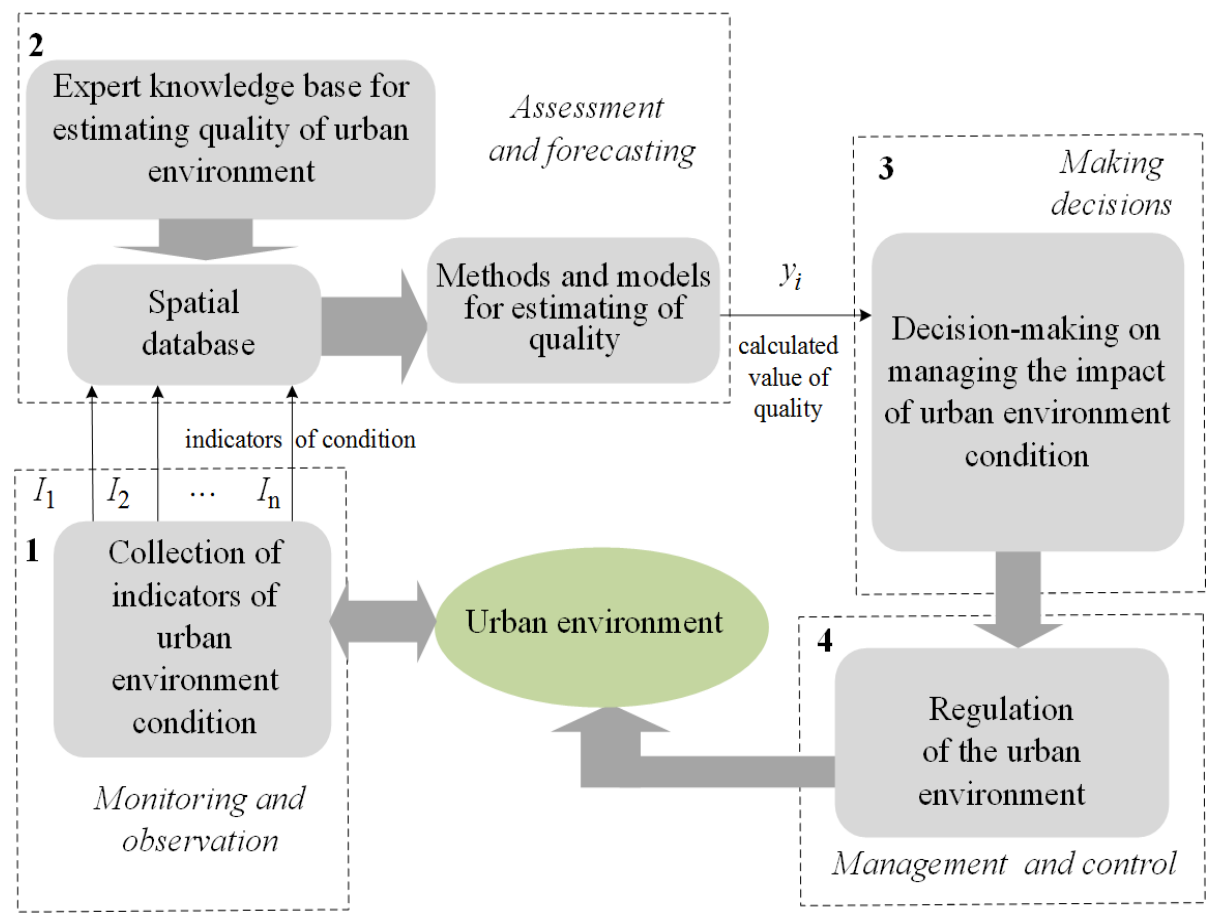

Fig. 4. Structure of intelligent technology for estimating of sustainable development of urban environment.

Consider phased intelligent technology components:

1 - monitoring and observation. The following types of information interaction $\Phi$ with the monitoring object can be used: $\left\{\phi^{1}, \phi^{2}, \phi^{3}, \phi^{4}, \phi^{5}, \phi^{6}, \phi^{7}, \ldots, \phi^{d}\right\} \in \Phi$, where $\phi^{1}-$ photogrammetric survey, $\phi^{2}-$ aerospace survey, $\phi^{3}-$ satellite measurements, $\phi^{4}-$ geodetic measurements on the ground, $\phi^{5}$ - information processing by means of geoinformation technologies, $\phi^{6}$ - data processing of field measurements, $\phi^{7}$ - infrared, radar survey, $d-$ cardinal number of set $\Phi$.

In the course of complex information interaction with the monitoring object, the characteristics of the current state of urban environment are determined:

$$
\left\{X_{l}^{P}\right\} \supseteq\left\{X_{l}^{P A}\right\}, \quad l \in L,
$$

where $X_{l}^{P}$ is the set of defined parameters,

$X_{l}^{P A}$ is the set of significant characteristics of the condition of urban environment.

$\mathbf{2}$ - assessment and forecasting of sustainable urban development. At this stage, three interrelated components are used: a spatial object-relational database, a fuzzy knowledge base, and knowledgeoriented methods for calculating the estimation of urban environment quality.

The spatial object-relational database schema is formally represented as: 
where $R=\left\{r_{q}, \mid q=\overline{1, n}\right\}$ is the set of database relations for which the attributes $A_{q}=\left\{a_{q p}, \mid p=\right.$ $\overline{1, m}\}$ and restrictions are defined as $S_{q}=\left\{s_{q k}, \mid k=\overline{1, h}\right\}$;

$L=\left\{l_{v}, v=\overline{1, z}\right\}$ is the set of relationships between the relations $\mathrm{R}$;

$\mathrm{C}$ - set of rules and restrictions that ensure database integrity and maintain data consistency.

A fragment of classes of objects of spatial database and classes of objects of fuzzy knowledge base for estimating the quality of urban environment is shown in Fig. 5. In addition to feature classes, class attributes, class operations and constraints that are imposed on relationships between feature classes are shown.

Creating justified decisions on managing sustainable development of urban territories requires the ability to analyze and optimize flows of energy, water and material resources in order to reduce the consumption of natural resources (Gerasimov et al., 2004; Greg et al., 2017). Therefore, the spatial database focuses on the spatial distribution of large number of buildings and households by functional zones and street blocks. Feature classes have been defined in accordance with the requirements of INSPIRE Data Specification (INSPIRE Data Specification, 2013). Using detailed information about residential buildings: type of building, size, location, year of construction and methods of regression analysis, can define the intensity of consumption of water, electricity, fuel for heating, which allows compensate the lack of small-scale data.

In order to unify the collection, storage and calculation of indicators of material and energy flows of urban environment in the database, it is proposed to create additional classes of thematic objects for storing indicators, which are classified in three sections: full flow of energy, that consumed by urban environment, products flow of energy and loss flow of energy. For example, object classes such as DomesticWaterConsum, HeatingInBuildingGas, ElectricityBuildingCup characterize, respectively, water consumption, natural gas consumption for heating and electricity consumption by each household or residents of residential buildings throughout the year. The considered classes of thematic objects model the consumed flow of resources, which for certain time and with certain efficiency has been used by society to meet its needs. Thematic classes of objects WasteRecycled, RenewableBuildingEnergy determine the total product produced (non-entropic energy flow (Rebane, 1984; Liiv, 1998)) in a certain time and technological capabilities of city economy subsystem. Thematic object classes EmissionCO2DomesticWaste, DomesticWaste, EmissionCO2HeatingBuild model energy loss flow, which characterizes missed opportunities of city economy subsystem. Proposed thematic classes of objects of city economy subsystem model a system of indicators of sustainable development that reflect technological, economic, environmental, social and other opportunities of urban environment as a whole.

Fuzzy Knowledge Base (FKB) provides storage, retrieval and generation of knowledge for estimating of urban environment quality. Knowledge is described by experts in the form of production rules. The knowledge base implements Sugeno logical inference algorithm. (Shtovba et al., 2016; Borisov et al., 2007).

To implement Sugeno algorithm (Rotshtein, 1999; Globa, 2008) an object-oriented approach was used. The diagram (Fig. 4) shows the most significant relationships and relationships between the classes of objects that are involved in the algorithm. Fuzzy Rules consist of Conditions and Conclusions, which in turn are Fuzzy Statements. Fuzzy Statement includes Linguistic Variable (SetLinguisticVariable) and term that is represented by fuzzy set (TermSetOfLinguisticVariable). Membership function is defined on fuzzy set, the value of which can be obtained using method (getValue). The relationship between FKB and SDB is provided through LinguisticVar class of objects. In general, $F K B$ provides storage of production rules in next form:

$$
\left[\prod_{k=1}^{n}\left(p_{k}=A_{k}^{j}\right] \rightarrow y_{i}\left(p_{1}, \ldots, p_{n}\right), i=\overline{1, m} .\right.
$$




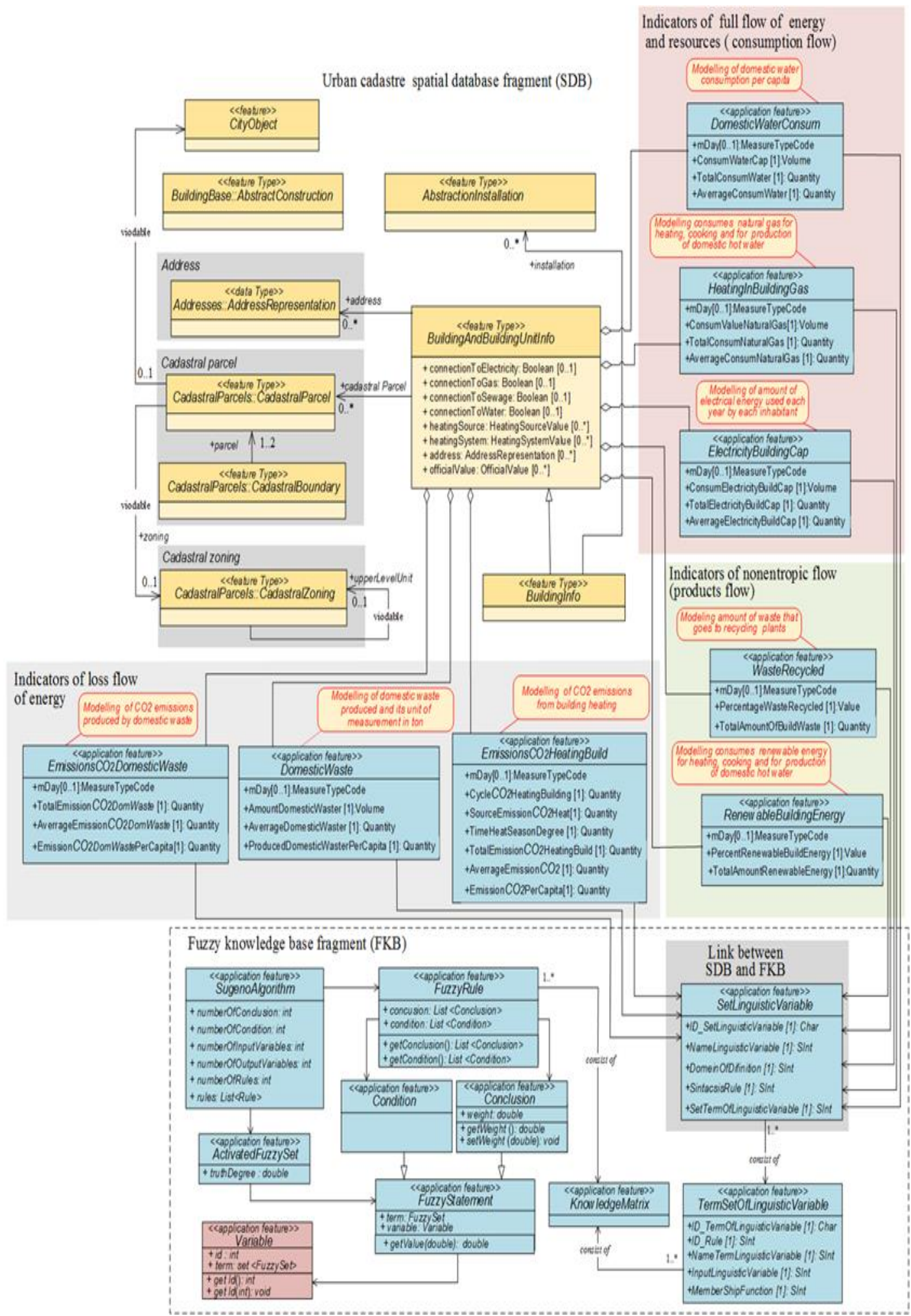

Fig. 5. Conceptual model for estimating of urban environment quality. 
Based on a fuzzy knowledge base and expert knowledge on the importance of characteristic values, fuzzification of indicators is carried out, which characterize the full flow of material and energy and information resources for certain time $-N(t)$, the free energy flow that ensures the life of city $-P(t)$ and loss energy flow $-L(t)$.

Fig. 6 shows an example of fuzzification of population density indicator $\mathrm{I}_{1}$ of the city with using appropriate term sets $A_{p_{1}}^{1}$ — "low density", $A_{p_{1}}^{2}$ — "average density", $A_{p_{1}}^{3}$ — "high density".

Each of term sets is characterized by corresponding membership function, which can be analytically defined by the following expression:

$$
\begin{gathered}
\mu_{p_{1}}^{1}(p)=\left\{\begin{array}{cc}
1, & p \leq 200 \\
\frac{p-400}{200}, & 200 \leq p \leq 400 \\
0, & p \geq 400
\end{array} ;\right. \\
\mu_{p_{1}}^{2}(p)=\left\{\begin{array}{cc}
\frac{580-p}{330}, & 250 \leq p \leq 580 \\
\frac{p-580}{220}, & 580 \leq p \leq 800 \\
0, & p \leq 600
\end{array} ;\right. \\
\mu_{p_{1}}^{3}(p)=\left\{\begin{array}{cc}
1, & p \geq 960 \\
\frac{960-p}{260}, & 700 \leq p \leq 900 . \\
0, & p \leq 600
\end{array}\right.
\end{gathered}
$$

The third part - methods and models for quality estimating of urban environment (Fig. 4) calculates the integral estimation of the efficiency indicator of urban environment metabolism based on Sugeno algorithm.

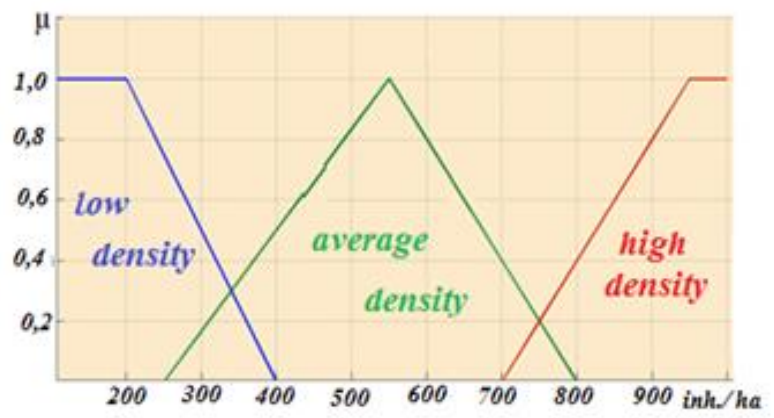

Fig. 6. Example of fuzzification of the city population density indicator.

Fuzzy mathematical model for estimating the efficiency indicator of urban environment as a set of Sugeno rules can be presented as (Giordano et al., 2014):

$$
R^{(i)}: \operatorname{IF} \prod_{i=1}^{m}\left(p_{k} I S A_{k}^{j}\right) \operatorname{THEN} y_{i}=\sum_{k=1}^{n} \frac{w_{k}}{W} \cdot f_{k}^{j}(x)
$$


where $i$ is number of TSK rules $(i=\overline{1, m})$;

$n$ - number of conditions;

$k$ - input variable number;

$p_{k}$ - input variable $(k=\overline{1, n})$;

$A_{k}^{j}$ - fuzzy set with associated membership function of $\mu_{k}^{j}, j \in\{1,2,3\}$;

$w_{k}$ - coefficient of an importance of input variable $p_{k} ; W=\sum_{i=1}^{n} w_{k}$.

The function $f_{k}^{j}$ is non-decreasing and complies with restrictions:

$$
0 \leq f_{k}^{j}\left(x_{k}\right) \leq 100
$$

3 - decision-making on managing the impact of urban environment condition. At this stage, the indicator of urban environment metabolism efficiency is used as a tool for preparing and making managerial decisions to improve the quality of population life. This indicator provides a multidimensional and multifactorial approach in making decisions on managing sustainable urban development.

4 - regulation of the urban environment. At this stage, the choice of alternative scenarios of urban planning is implemented, which will allow end users to change the goals and indicators of the city sustainable development.

\section{RESULTS AND DISCUSSIONS}

For testing the proposed intelligent technology for estimating of potential, real and lost opportunities of urban environment, two specific post-Soviet cities Odessa and Krivyi Rih were selected. Extremely different in terms of size and population, these cities were chosen because of their specificity: Odessa is a vivid example of tourist city on seashore, while Krivyi Rih represents a vivid example of post-industrial city with difficult environmental situation. The reliability and validity of obtained integrated estimations of sustainable development of cities Odessa and Krivyi Rih is confirmed by similar indicators of sustainable development for cities Barcelona and Lugano.

For preparing the initial data, GIS capabilities were used to form geospatial models and thematic layers according to indicators that presented in table 1 . Table $\mathbf{1}$ has 37 basic indicators that characterize metabolism of each from three urban environment subsystems of cities Krivyi Rih and Odessa.

The basic component of the urban metabolism efficiency is geographical data, that presented in digital form on spatial objects and includes information about their spatial and non-spatial properties. Intelligent technology is implemented in MatLab software (The MathWorks Inc) based on thematic cartographic data generated in ArcGIS 10.

The initial data for cities Krivyi Rih and Odessa are based on open sources (Kryvyi Rih strategic development plan till 2025, 2016; Strategy of economic and social development of the city Odessa until 2022, 2013).

Fig. 7 shows changes in the indicator of urban environment efficiency depending on changes in the share without carbon transport and average mileage of vehicles in urban cycle for cities (a) Odessa and (b) Kryvyi Rih. The surface can be interpreted as the landscape of efficiency for the scenario that includes changes to only two of considered input variables. For comparison, landscapes of the urban environment efficiency of the city (c) Lugano in space of these two variables are shown. 
a)

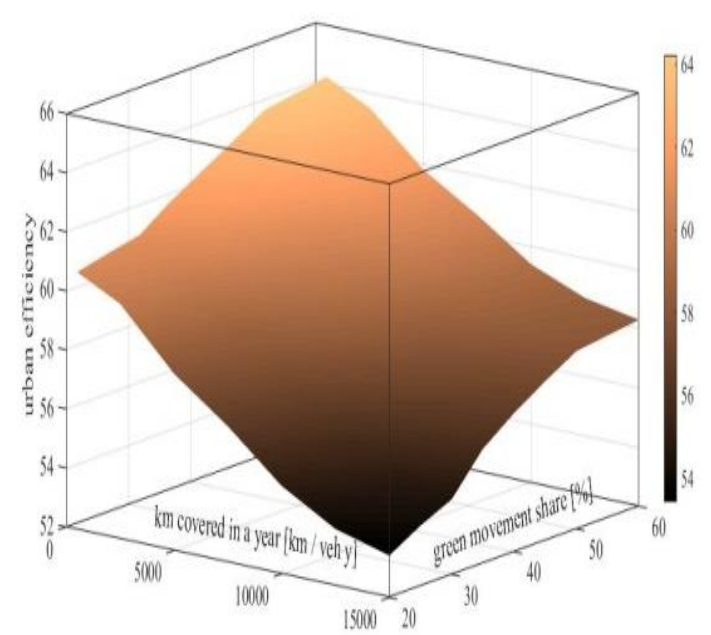

b)

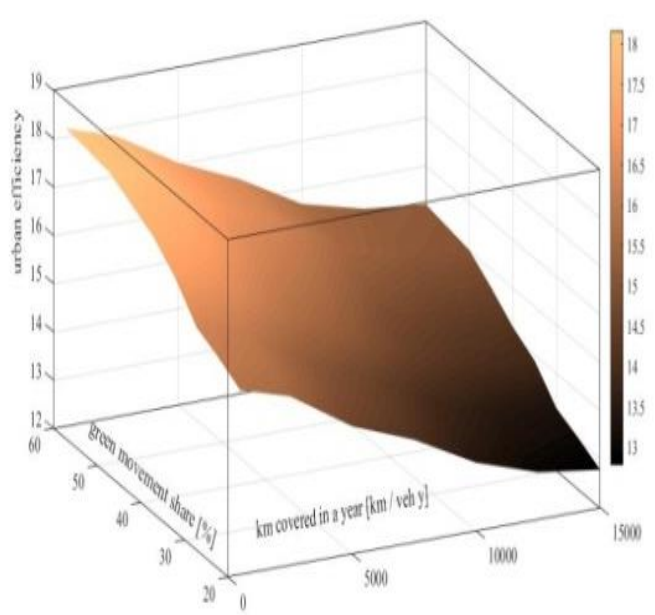

c)

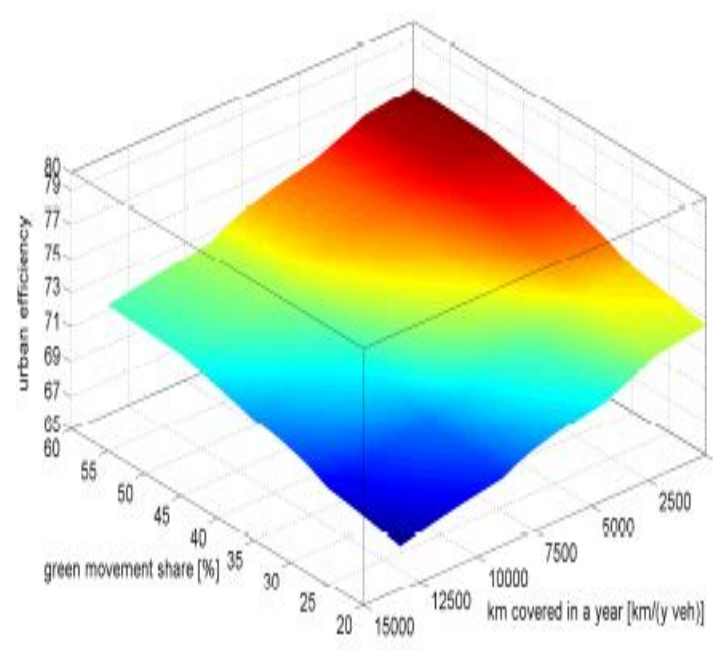

Fig. 7. The influence of green movement share and average volume of km covered in a year on changes of urban environment efficiency for cities (a) Odessa, (b) Kryvyi Rih in comparison with city (c) Lugano.

Fig. 8. shows the contour lines of the estimation indicator of sustainable urban development of cities a) Odessa and b) Kryvyi Rih in context of two-dimensional input space. This performance gives a new knowledge about ways of the urban environment enhancing and, consequently, facilitates the adoption of evidence-based decisions: for example, the contour lines show the direction of changes in variables that are neutral from the point of view of the efficiency of cities. Each contour line is interpreted as a possible compromise between the real and lost possibilities of possible transformation of the urban environment.

In Fig. 8 we can see how the increase in the average car mileage in the urban cycle can be compensated by increasing shares of no carbon transport. The share without carbon transport, which can compensate for the increase in the average mileage of cars in the urban cycle, is different for (a) Odessa and (b) Kryvyi Rih. The direction, along which the contour lines are closer to each other, shows the maximum sensitivity of the indicator sustainable development of the urban environment. 
a)

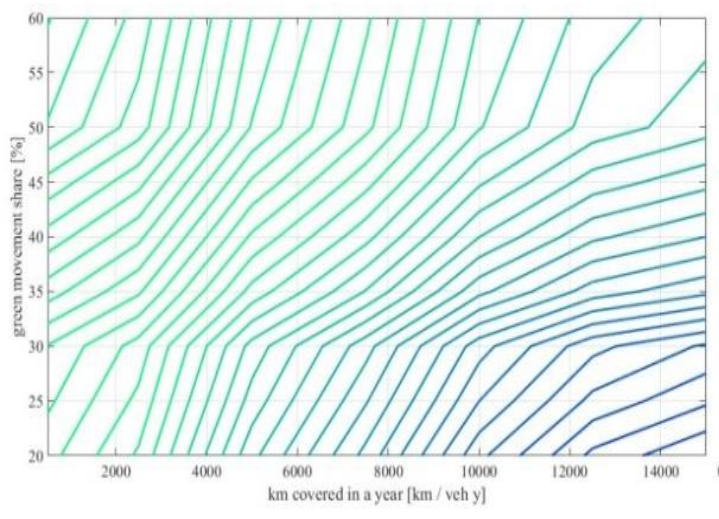

b)

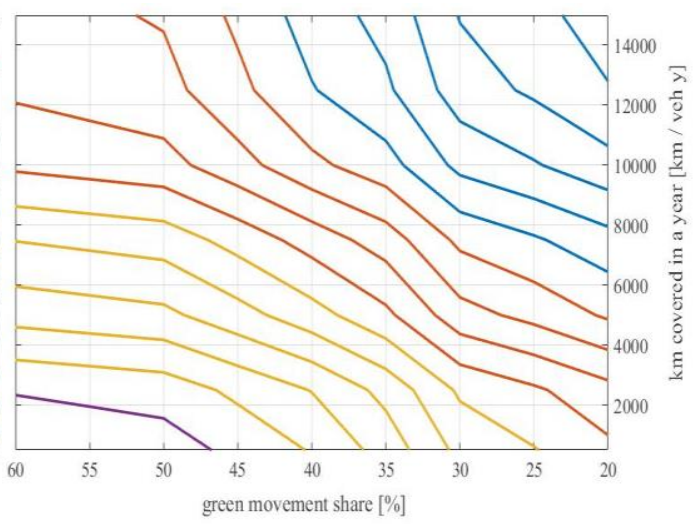

Fig. 8. Contour lines of the indicator of urban environment efficiency: (a) Odessa, (b) Kryvyi Rih.

The following Fig. 9 shows the reaction of the indicator of the effectiveness of the urban environment to changes in emissions of $\mathrm{NO}_{\mathrm{x}}$ (recall that $\mathrm{NO}_{\mathrm{x}}$ emissions have two main sources: heating and transport). The surfaces in Fig. 9 characterize a scenario change indicator of the effectiveness of the urban environment for the case of only changes in $\mathrm{NO}_{\mathrm{x}}$ emissions on example of cities Odessa and Kryvyi Rih.

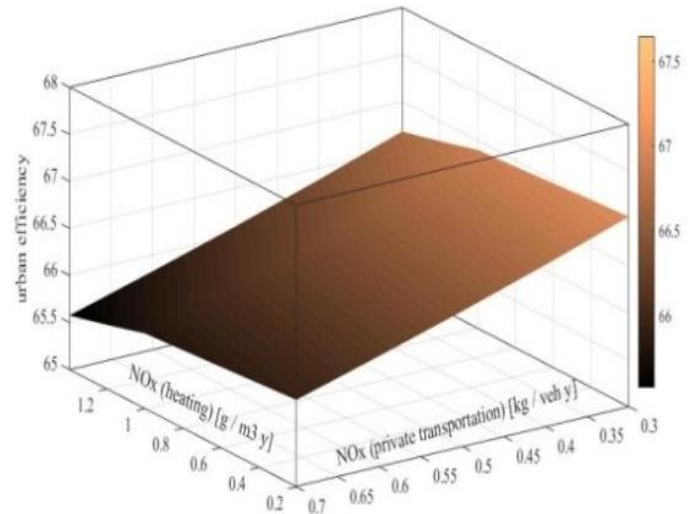

a)

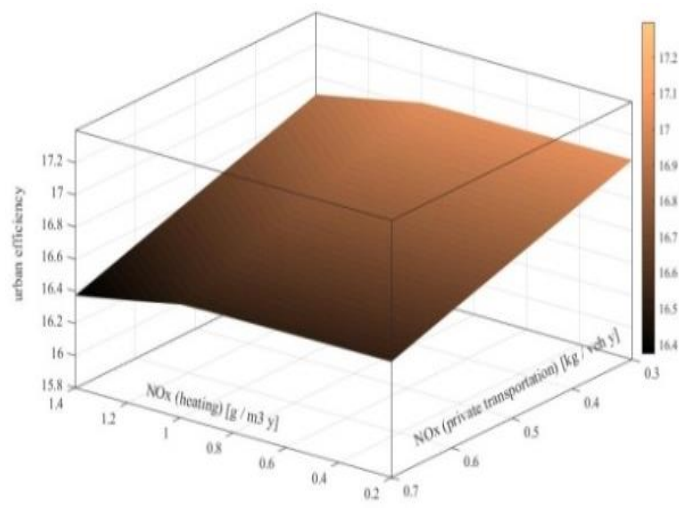

b)

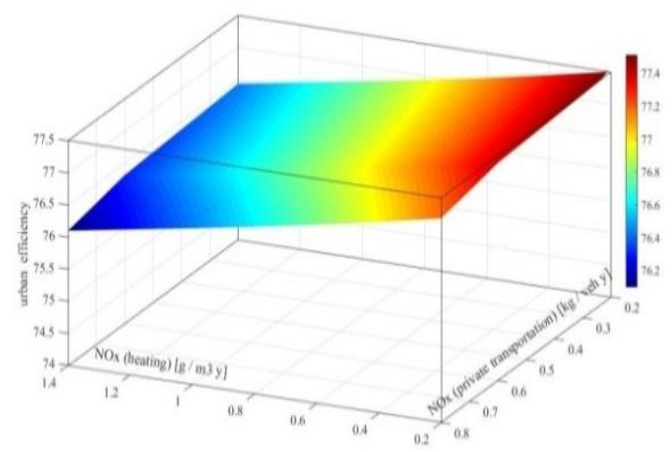

c)

Fig. 9. The indicator of urban environment efficiency for changes in $\mathrm{NO}_{\mathrm{x}}$ emissions:

(a) Odessa, (b) Kryvyi Rih, (c) Barcelona. 
The calculated values of potential, real and lost opportunities for each of the subsystems of the urban environment (see Fig. 1) are presented as Kiviat Diagram (Fig. 10).

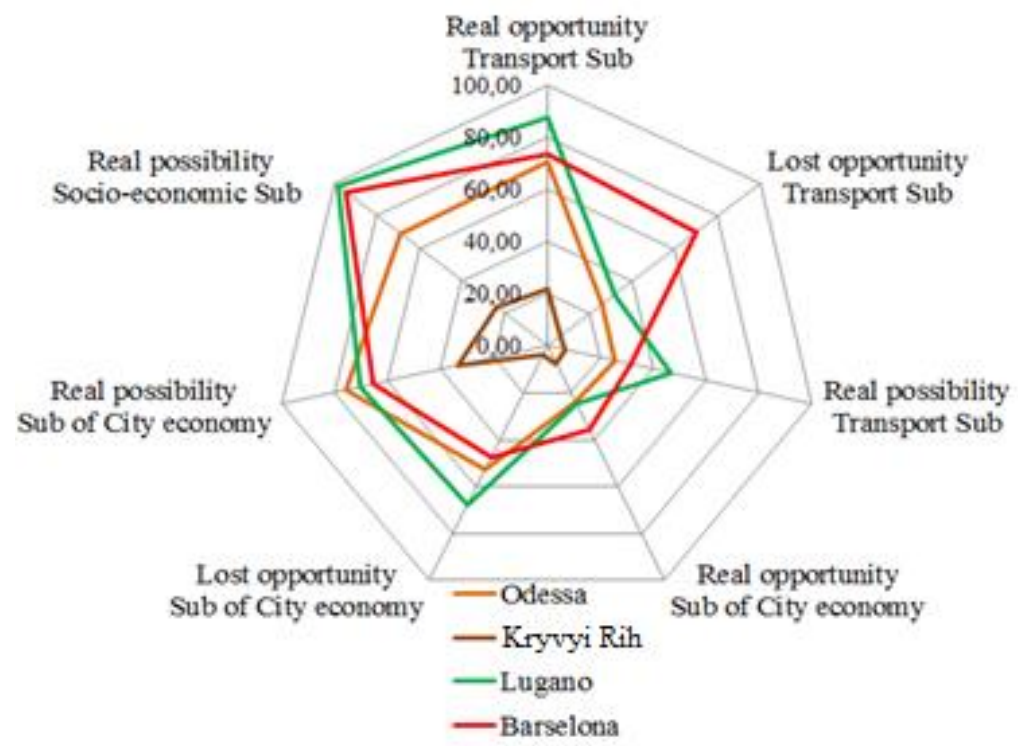

Fig. 10. Values of seven intermediate performance indicators of urban environment subsystems for cities Odessa, Kryvyi Rih in comparison with cities Lugano and Barcelona.

A comparison of indicators of integrated estimations of sustainable urban development for cities Odessa, Kryvyi Rih with similar estimations for cities Barcelona and Lugano, which were obtained as a part of the program for monitoring the sustainable development of European Union cities, is shown in Fig. 11.

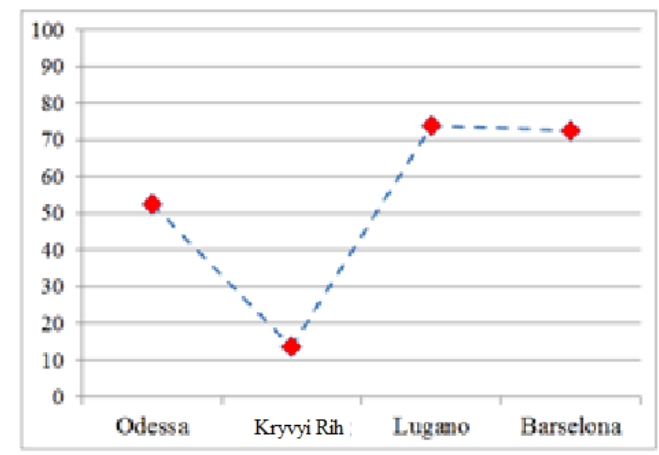

Fig. 11. Computation results for cities Odessa, Kryvyi Rih in comparison with cities Lugano and Barcelona.

A brief analysis of results based on proposed intelligent technology of potential real and lost opportunities of urban environment revealed key problems of the socio-economic and territorial development of post-Soviet cities. Low indicators are explained by the strong zoning of the territory (for industrial and residential), low mobility of the population, low incomes, lack of modern technologies for processing industrial and household waste and poor market development without carbon vehicles. Thus, the new conditions that shape the modern urban environment - globalization, the neo-tertiary economy, and new intellectual information technologies - should reconsider the modern urban planning paradigm so that modern urban projects are based on assessing potential, real and lost opportunities in order to ensure sustainable development of the urban environment. 


\section{CONCLUSIONS}

Approach based on the integration of capabilities of modern GIS and intelligent technologies for estimating the quality of the urban environment is a new, promising area for the development of tools for managing the sustainable development of urban areas. In the framework of proposed intellectual information technology, the following results were obtained:

- the principle of information system creating in the form of an object-oriented database of spatial data has been developed, which contains large arrays of heterogeneous spatially distributed indicators of real, lost and potential capabilities of Ukrainian cities;

- production-type knowledge base has been created for storing expert knowledge on the boundary and maximum permissible environmental, socio-economic and urban development indicators of the urban environment;

- based on formal methods and using expert estimates, a methodology has been developed for estimating the potential, real and lost capabilities of the urban environment based on qualitative characteristics;

- proposed intelligent technology for estimating the quality of the urban environment allows to generate possible scenarios for changing the efficiency indicator depending on the selected space of input characteristics.

Using of proposed intelligent technology for estimating of urban environment quality is deeply interdisciplinary in nature and is important for ensuring decision-making on managing sustainable development of urban areas.

\section{R E F E R E N C E S}

Acebillo J. (2013). New Urban Metabolism. Barcelona / Lugano. Barcelona - New York: Editorial ActarD., 244 p.

Bettencour L. A., Lobo J., Helbing D., Kühnert V., West G. B. (2007) Growth, innovation, scaling, and pace of life in cities. Proceedings of the National Academy of Sciences, 104 (17), 7301-7306.

Bolshakov B. E., Kuznetsov O. L. (2010) Sustainable development: universal principle for the synthesis of natural, technical and social knowledge. Bulletin of the Russian Academy of Natural Sciences, 10 (3), 3-9, (in Russian).

Bolshakov B. E., Ryabkova. S. A. (2009) Emergence and main problems of concept of "Sustainable Development" entering into world politics and science. An appendix to the training complex "Theory and Methodology of Designing the Sustainable Development of Socio-Natural Systems". Dubna, 210 p, (in Russian).

Bolshakov B. E. (2008) Theory and Methodology of Designing Sustainable Development of Socio-natural Systems. 143 p. Available: http://www.aup.ru/books/m536 [Accessed June 2020], (in Russian).

Borisov V., Kruglov V., Fedulov A. (2007) Fuzzy models and networks. - M.:Hot line - Telecom, 284 p, (in Russian).

D2.8.III.2 INSPIRE Data Specification on Buildings - Draft Technical Guidelines. (2013) INSPIRE Thematic Working Group Buildings, 309 p.

Gerasimov B., Devisinuck M., Subach I. (2004) Decision support systems: design, application, estimation of efficiency. Monograph, Sevastopol, 320 p. Available: https://studfile.net/preview/5367046 . (in Russian).

Giordano P., Capuno P., Vancheri A. (2014) Fuzzy Evaluation of Heterogeneous Quantities: Measuring Urban Ecological Efficiency. Ecological Modeling, 288, 112-126. Available: https://doi.org/10.1016/j.ecolmodel.2014.06.001.

Globa L., Ternovoy O., Shtogrina M. (2008) Creating fuzzy knowledge bases for intelligent control systems. Computing, International Scientific and Technical Journal, 7 (1), 70-79. (in Ukrainian). 
Greg Scott, Abbas Rajabifard. (2017) Sustainable development and geospatial information: a strategic framework for integrating a global policy agenda into national geospatial capabilities. Geo-spatial Information Science, 20:2, 59-76. Available: https://doi.org/10.1080/10095020.2017.1325594 .

Hasanova S. S., Pogosyan L. V., Novikov A. V., Batashev R. V. (July 2019) Urban Geographic Information System: Features of Implementation and Management. International Journal of Innovative Technology and Exploring Engineering, 8 (9). Available: https://doi.org/10.35940/ijitee.H7505.078919/ .

Kennedy C.A. et al., (2015). Energy and Material Flows of Megacities. PNAS, 112 (19), 5985-5990. Available: https://doi.org/10.1073/pnas.1504315112.

Kryvyi Rih strategic development plan till 2025. (2016) Executive Committee of Kryvyi Rih City Council. Department of Economics. Public Utilitym Kryvyi Rih City Development Institution of Kryvyi Rih City Council, 100 p. Available: https://kr.gov.ua/ua/st/pg/100415583959267_s [Accessed July 2020]. (in Ukrainian).

Liiv E.H. (1998) Infodynamics, Generalized Entropy and Negentropy. - Tallinn: Juhisjelu, 200 p.

Mikhno O., Patrakeyev I. (2018) Quality evaluation method of the city environment. Visnyk Taras Shevchenko National University of Kyiv. Military-Special Sciences, 2 (39), 29-39. Available: https://doi.org/10.17721/1728-2217.2018.39.29-39 . (in Ukrainian).

Newman P. (1999) Sustainability and Cities: Extending the Metabolism Model. Landscape and Urban Planning, 44, 219-226.

Paola C., Giulia P., Marco B. (2016) Urban Metabolism Analysis as a Support to Drive Metropolitan Development. Procedia Engineering, 161, $1588 \quad-\quad$ 1595, Available: https://doi.org/10.1016/j.proeng.2016.08.631 .

Patrakeyev I, Ziborov V. (2019) Using fuzzy sets in the estimation system of the efficiency of urban environment metabolism (on the example of cities of Ukraine). Geodesy and cartography, 45 (3). 102-109. Available: https://doi.org/10.3846/gac.2019.7699.

Patrakeyev I., Ziborov V., Lazorenko-Hevel N. (2017) Methods of Evaluation of the State and Efficiency of the Urban Environment, ISPRS Ann. Photogramm. Remote Sens. Spatial Inf. Sci., IV-5/W1, 43-49, Available: https://doi.org/10.5194/isprs-annals-IV-5-W1-43-2017.

Rebane K.K. (1984) Energy, Entropy, Habitat. Tallinn: Valgus, 159 p, (in Russian).

Rotshtein P. (1999) Intelligent identification technologies. Vinnytsia: University-Vinnytsia, 320 p. (in Russian).

Shtovba S.D., Mazurenko V.V., Tylets R.O. (2016) Fuzzy identification information technology for the synthesis of accurate, compact and interpretable knowledge bases. Computer Sciences and Telecommunications. 1 (47). 8-22, (in Russian).

Strategy of economic and social development of the city Odessa until 2022. (2013) Odessa:TPP, 80 p. Available: https://omr.gov.ua/images/File/DODATKI2013/Strategiya_Odessa_Ukr.pdf [Accessed July 2020], (in Ukrainian).

Sustainable Urban Metabolism for Europe (2009). Urban development and urban metabolism: A spatial approach. Work Package 1. Available: http://sume.at/project downloads [Accessed July 2020].

Yanitsky O. N. (2013) Metabolic concept of the modern city. Sociological science and social practice, 3, 6-32, (in Russian). 